García Rams, María Susana.

Doctora en BBAA, profesora de animación, Dpto. dibujo. UPV.

Sebastian, Samuel.

Cineasta y dramaturgo.

\title{
Animación, conciencia, mediación. Laboratorio animado para una cultura inclusiva
}

\section{Animation, awareness, mediation. Animated laboratory for an inclusive culture}

TIPO DE TRABAJO: Comunicación.

PALABRAS CLAVE

Animación, conciencia, mediación, cultura, inclusión, taller.

KEY WORDS

Animation, awareness, mediation, culture, inclusion, workshop.

RESUMEN

Animación, conciencia, mediación es un proyecto de innovación premiado en el Concurso de Ideas del Laboratorio de Cultura Inclusiva de Las Naves promovido por el Ayuntamiento de Valencia.

El objetivo fundamental de este proyecto es generar en las Naves un espacio abierto, inclusivo, accesible y participativo, sensible a la realidad individual y particular de la ciudadanía, favorecedor del intercambio, acogedor de la diversidad y manteniendo siempre una perspectiva de género. Esta experiencia se reproducirá en otras ciudades y centros culturales.

La animación tradicionalmente ha sido una forma de creación elitista y masculinizada. Elitista por la cantidad de medios y conocimientos técnicos que requiere y masculinizada porque tanto los creadores como las películas han tenido generalmente un protagonismo netamente masculino y heteropatriarcal. Sin embargo, nuestro proyecto da la vuelta a esta perspectiva ya que muestra cómo la animación puede ser realizada y protagonizada por diferentes tipos de personas, sin que sean necesarios unos grandes medios, por ejemplo mediante la reutilización de materiales, y además puede servir como una herramienta de empoderamiento, educación y concienciación.

A partir del cine de animación se trata de dar voz a quienes no la tienen, mostrar a los colectivos invisibilizados, denunciar las injusticias. Igualmente, las técnicas y procesos de la animación, como producción cultural rica en matices, que aúnan lo sencillo y lo complejo, lo analógico y lo tecnológico, fomentan la creación sin condicionantes para que participen en este proyecto personas con funcionalidad diversa, adolescentes, refugiadas o migradas, mujeres, colectivos LGTBIQ+ y otras minorías sociales como personas mayores o en riesgo de exclusión, de una forma colaborativa y a través de las diferentes asociaciones comprometidas con él.

El proyecto actúa como un Laboratorio animado para una cultura inclusiva, facilita el aprendizaje y establece vínculos entre las personas y los diferentes colectivos a través de una creación grupal.

ABSTRACT

Animation, awareness, mediation is an innovation project awarded in the Contest of Projects for the Inclusive Culture Laboratory of Las Naves promoted by the Valencia City Council. 
The main goal of this project is to generate an open, inclusive, accessible and participatory space in the Naves, sensitive to the individual and singular reality of the citizens, favoring exchange, welcoming diversity and keeping a gender perspective. This experience will be reproduced in other cities and cultural centers.

Animation has traditionally been an elitist and masculinized form of creation. Elitist because of the amount of media and technical knowledge required and masculinized because both creators and films have generally had a distinctly masculine and heteropatriarchal perspective. However, our project turns this perspective as it shows how animation can be made by people of different kind, without the need for large budgets, for example reusing materials, and can also serve as a tool for empowerment, education and awareness.

From the animation we will give voice to those who do not have it, showing invisible collectives, denouncing injustices. Techniques and processes of animation, as a cultural production rich in nuances, that joins the simplicity and the complexity, the analogical and the technological. In this way, creation is made without conditions so that people with diverse functionality, teenagers, refugees or migrants, women, LGTBIQ + groups, social minorities, elder people or those who are suffering risk of exclusion, can collaborate in our project through the committed associations.

The project is an animated laboratory for an inclusive culture, facilitates learning and gives links between people and different groups in order to make a collective creation.

\section{INTRODUCCIÓN}

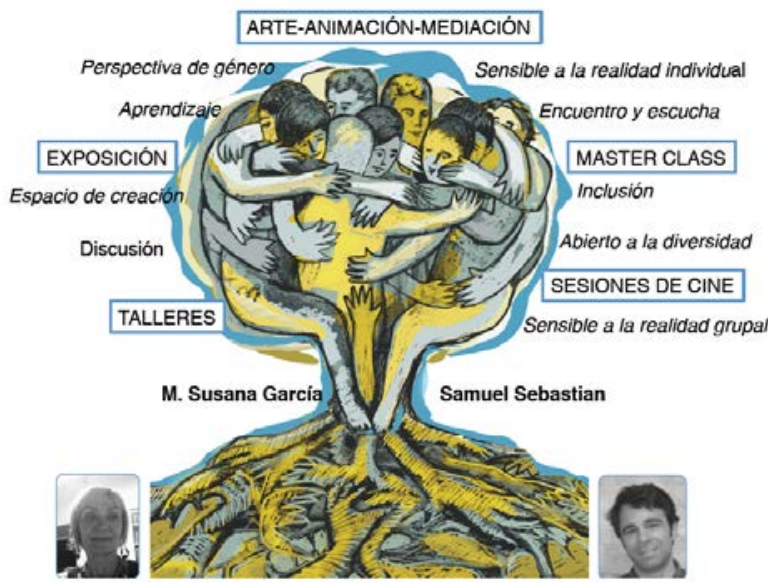

Figura 1 Elaboración propia. Imagen representativa del proyecto.

El arte actúa como una vía de expresión que permite al individuo conectar con sus propias dificultades y capacidades y así expresarlos para si mismo o para otros de manera metafórica en sus creaciones. La expresión de ese universo propio a través de las producciones artísticas es un recorrido a través de contenidos subconscientes que se hacen visibles más fácilmente mediante la representación artística, constituyéndose así en un elemento de mediación hacia el individuo y el grupo con lo social, ya que pone en valor su capacidad de re-creación. (Moreno, 2016). ${ }^{1}$

El papel del cine en la transformación de la conciencia ha sido y es fundamental, ya que en su mas profundo significado y fin recoge los aspectos sociales de la cultura en la que surge, y se nutre de temáticas profundas e imágenes inspiradoras, que llevan al espectador a una reflexión sobre si mismo y lo que le rodea. Según Zunzunegui (1984) para McLuhan ${ }^{2}$ : "el cine, nos permite enrollar el mundo real en un carrete para volver a desenvolverlo cual si fuese una alfombra mágica de fantasía" ( $p$ 271).

\footnotetext{
${ }^{1}$ En esta obra la autora; arteterapeuta y mediadora artística, sitúa a Las artes como una herramienta valiosa y útil para trabajar en contextos sociales y comunitarios exponiendo como en los centros donde se atiende a personas con problemas sociales diversos, se desarrollan talleres y proyectos de teatro, danza, fotografía, vídeo, música, artes plásticas y visuales y de escritura creativa, en los que los sujetos se implican en procesos de creación.

${ }^{2}$ El comentario original del autor lo podemos encontrar en McLuhan, M. (1996). Comprender los medios de comunicación. Las extensiones del ser humano. (1a ed). Barcelona:Editorial Paidós. p 292.
} 
El propósito principal de este proyecto artístico, inclusivo y de investigación es la acción-reflexión, para lo que se diseñó un programa que contemplara la creación, el aprendizaje, la discusión, el encuentro y la escucha, que estuviera abierto a la diversidad, fuera accesible y participativo, que recogiera y respondiera a la realidad individual y grupal de las personas y contemplara una perspectiva Intercultural, intergeneracional y de género.

Para llevar a cabo este planteamiento innovador desde esta perspectiva tan amplia y transversal, hemos trabajado conjuntamente con un grupo de profesionales comprometidos con lo social, desde la educación, la animación, el audiovisual, la asistencia social, la Mediación Artística y la Arteterapia, para ofrecer propuestas concretas y vinculadas entre sí: exposición, talleres, conferencias, pases de películas y debates, con el objetivo de dinamizar las relaciones de los participantes y visitantes y con ello, favorecer el conocimiento mutuo entre grupos diversos: mujeres refugiadas, personas de la tercera edad, migrantes, jóvenes, niños en riesgo de exclusión, personas LGTBIQ+ y otros ciudadanos y ciudadanas. Utilizamos el aprendizaje de las técnicas sencilla de la animación como crisol que les reúna, les haga sentir participes de algo común y les ofrezca reflexión desde lo lúdico. Para que compartan aprendiendo animación y los mismos participantes puedan desarrollar una pequeña pieza animada con la que se identifiquen, de la que sean artífices y sirva para darles voz.

\section{METODOLOGÍA}

"Animación, conciencia, mediación" es un proyecto de innovación a través del audiovisual premiado en el "Concurso de Ideas del Laboratorio de Cultura Inclusiva de Las Naves", promovido por el Ayuntamiento de Valencia en 2018. El proyecto posee una metodología de investigación cualitativa y de acción-reflexión, aunando las experiencias acumuladas en los diferentes campos de conocimiento de los responsables del proyecto y a la vez, realizando un trabajo colaborativo con los diferentes implicados, para ir diseñando las acciones y realizando el análisis de resultados a la vez que, recopilamos todo un material escrito y audiovisual que se unificará al final del proyecto en una publicación y documental audiovisual.

La elección de la animación como vehículo es debido a la facilidad de comprensión del lenguaje, al uso de metáforas y simbolismos que facilitan la expresión de emociones y sentimientos de una manera mas universal y entendible, de manejar elementos sencillos y cotidianos y darles valor narrativo, al poder contar sin palabras. Además de su capacidad de seducción para el gran público, hoy día es un medio de expresión y concienciación en el que trabajan gran cantidad de autores y autoras en todo el mundo para denunciar y ayudar, alertar y concienciar, desvelar para implicar y sobre todo para humanizarnos y crear vínculos de empatía con el espectador a cerca de lo que pasa en otros lugares y a otras gentes unas veces muy lejanos, pero otros muy cercanos a nosotros/as.

Beneficiarios:

Hemos seleccionado los diferentes colectivos a partir de un profundo trabajo de investigación con diversas organizaciones sociales, que nos respaldan, así como de las experiencias previas de trabajo con usuarios diversos, desde los lugares afines de actividad de los profesionales implicados en el proyecto.

Asociaciones colaboradoras en todas las actividades y con las que seguiremos en contacto para verificar los beneficios de la experiencia y nuevos acciones de futuro:

- Comisión de Ayuda al Refugiado- País Valencià (CEAR-PV)

- Asociación Alanna

- Red Europea contra la Pobreza y la Exclusión Social (EAPN)

- Hogares Compartidos

- $\quad$ ONGd Atelier

- Fundación Adsis

- Fundacion Terapia de Reencuentro

- Instituto Terapia de Reencuentro

- $\quad$ AVATT, Asociación Valenciana de Arteterapia.

- IDECART, Instituto de Investigación y Desarrollo de los Procesos de Creación y Arteterapia

- Saltarinas

- LAMBdA

- Comité antisida de València 
Los/las usuarios/as podrán participar de forma prioritaria en todas las actividades y tanto ellos como ellas, como las asociaciones a las que pertenecen, tendrán un espacio de debate destacado en cada actividad.

Entidades que también colaboran y respaldan esta iniciativa:

- Las Naves.

- Vicerrectorados de Cooperación y Cultura - Universitat Politècnica de València.

- Máster en Arteterapia- UPV

- Máster en Animación- UPV

- Prime the animation. International Student Festival.

- Grupo de Investigación Animación Arte e Industria, UPV

\section{DESARROLLO}

El proyecto "Animación, conciencia, mediación" está pensado en varias fases que se desarrollarán de forma paralela y complementaria:

1) Animación para transformar el mundo. La exposición.

2) Las Masterclass: Animación y género rompiendo estereotipos.

3) El taller en animación. Como herramienta inclusiva y de mediación.

Se contempla la documentación de cada una de las actividades, en forma de entrevistas y artículos escritos por cada uno de los participantes en el proyecto, grabaciones de todos los eventos (con las restricciones y autorizaciones correspondientes, en función del colectivo y edad de los participantes) y edición de las animaciones frutos de cada taller. Todo ello formará parte de una publicación por la editorial Sendemà y de un audiovisual producido por GAMANprod. como base documental y de consulta para otros investigadores.

\section{Animación para transformar el mundo. La exposición.}

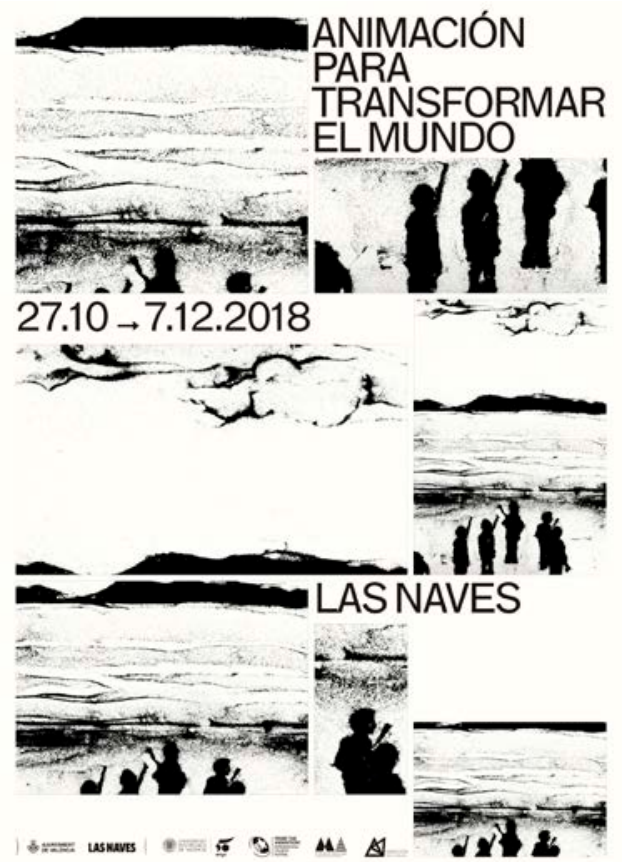

Figura. 2. Cartel de la exposición. Diseño de Iban Ramón
La primera de las acciones del proyecto fue la exposición "Animación para transformar el mundo", con la finalidad de mostrar a través de la selección de dos autores y dos autoras preocupados por lo social y comunitario desde la animación de autor comprometida, este tipo de arte y su vínculo con la realidad social y personal de ciertos colectivos representados. Y así visibilizar, difundir, compartir, incluir, unir; asociaciones, usuarios y otros actores sociales, instituciones, cooperantes y ciudadanos y con ello crear conciencia, viendo a través del tamiz de estas creaciones audiovisuales, las situaciones de otros, reflexionando sobre las mismas, encontrando nuestro lugar en este mundo y la responsabilidad de lo que sucede en el mismo.

La propuesta expositiva de comisariado ha cuidado qué mostrar y cómo, la paridad de autores, las temáticas tratadas y diseñando el espacio para acercar fácilmente los vocabularios de animación en su proceso a todo tipo de personas. También ha sido primordial vincularla con el Festival Prime the animation y la Universitat Politècnica de València como lugar de conocimiento y labor importante de compromiso con la sociedad. 
Animación, Conciencia, Mediación. Laboratorio animado para una cultura inclusiva. IV Congreso INTERNACIONAL DE INVESTIGACIÓN EN ARTES VISUALES ANIAV 2019 IMAGEN [N] VISIBLE]

http://dx.doi.org/10.4995/ANIAV.2019.9069

Mario Torrecillas Barcelona. Director de Pequeños Dibujos Animados un proyecto audiovisual que nace con el objetivo de educar en cine, en diversidad cultural pero especialmente mostrar la creatividad y el pensamiento de los niños a través de la animación, el dibujo y la música. El cortometraje Mamá a los 15 (2018) es uno de los resultados de un proyecto de Educación para el Desarrollo de la ONGD Medicus Mundi Sur. En este proyecto se realiza un trabajo creativo con estudiantes de 13 a 17 años, en el cual los protagonistas son ellos y ellas. Se han realizado varios talleres de cine de animación con alumnos y con sus profesores. Los mismos chicos y chicas han creado las animaciones que aparecen en este corto, como fondo ilustrativo de las entrevistas realizadas a cuatro jóvenes madres para sensibilizar en la prevención de la maternidad a corta edad, un tema que consideramos muy importante, necesario que se visibilice y del que se ha de hablar.

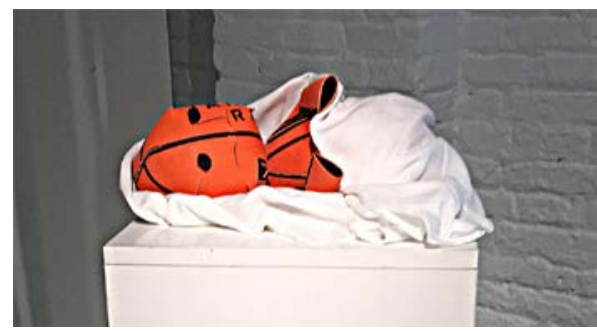

Jugábamos en el recreo con un balón de futbol o de baloncesto debajo de la ropa a que estábamos embarazadas, y a año siguiente nos quedábamos embarazadas la mayoría. ${ }^{3}$

Figura. 3. "Manolito". Personaje de Stop Motion construido con un balón de baloncesto. Mario Torrecillas.

Isabel Herguera es una artista que pinta, generalmente, con acuarelas, crea personajes, realiza historias con dibujos, ilustra sus cuadernos de viaje y dirige películas de cine y vídeo con animación. Licenciada en Bellas Artes por la Universidad del País Vasco continua en la Academia de Artes de Düsseldorf donde tiene de profesor al artista Nam June Paik y en el California Institute of the Arts, en Los Angeles, al maestro pionero de la animación Jules Engel.

Quería dar la vuelta al mundo, pero no tenía dinero, así es que ofrecí a cambio hacer talleres y esa sí como comencé a desarrollar una práctica que se ha convertido en una fuente de inspiración para mi...y a raíz de los resultados he repetido este formato ${ }^{4}$

Las obras seleccionadas de la autora han sido dos:

Sultanas Mehendi (2013) por el formato de realización en base al taller con mujeres en la India y la visibilización de su situación así como del bienestar que les proporciona este tipo de actividad en cuanto a que son ellas mismas quienes hacen los dibujos que se animaran y ponen la voz, siendo las protagonistas del filme. Los dibujos de la muestra se convierten en símbolos que hablan.
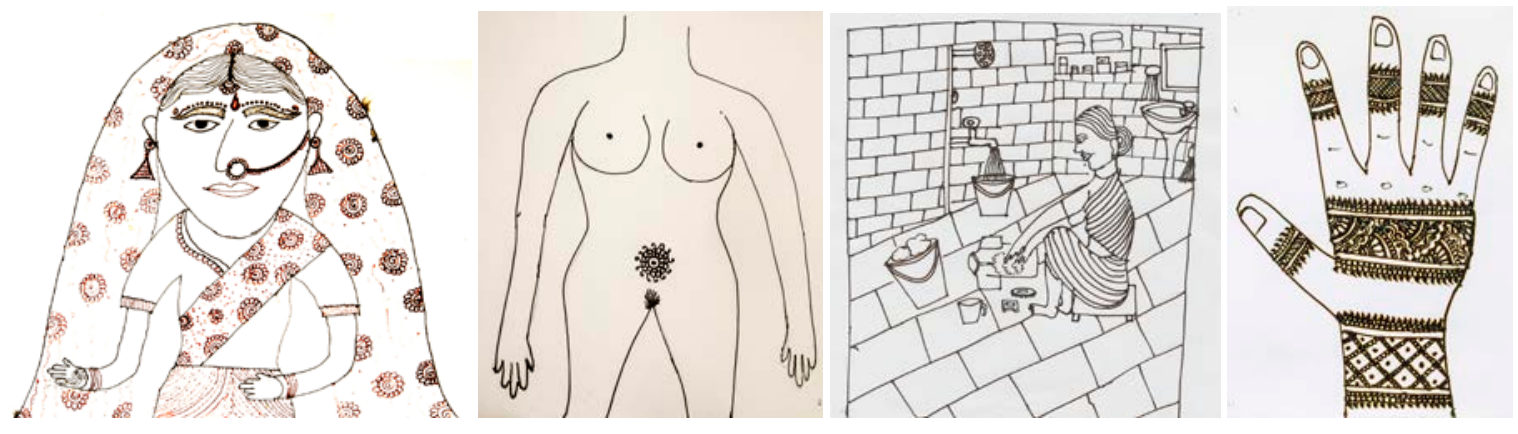

Figura. 4. Imágenes de la exposición que muestran los dibujos realizados en el taller de Isabel Herguera por mujeres Mehendi con Henna y barro sobre papel.

\footnotetext{
${ }^{3}$ Fragmento de la entrevista a una de las jóvenes mamas del corto de Mario Torrecillas extractado de García Rams, S y Sebastian, S ( 2018 , 10, 28) Animación, conciencia, mediación. Animación para transformar el mundo.[video] https://vimeo.com/309460328 y en https://animacioninclusiva.wordpress.com/ , GAMANprod, (03:53-03:55)

${ }^{4}$ Ibidem (05:04 a 05:20)
} 
Letters of the Jungle (2018). La propuesta es de una gran riqueza ya que muestra esa universalidad de los sentimientos al traducir las duras vivencias materializadas en cartas y escritas por excombatientes de las FARC, a escenas animadas con diferentes técnicas por estudiantes de animación de cinco países: Universidad Pontificia Javeriana de Bogotá, Colombia, Kunsthochshule für Medien de Colonia, Alemania, Central Academy of fine Arts, China, FAD. Universidad Nacional Autónoma de México, National Institute of Desing, India y supervisada por artistas-docentes de escuelas participantes: chengkemei, Wangliming, Sekhar, Mukherjee, Cecilia Traslaviña, Ziluinas Lilas, Tania de león e Isabel Herguera.

Del proceso se expusieron las cartas, una secuencia completa animada sobre papel, fragmentos de la preproducción, recortes y marionetas, un libro de memoria del proyecto y el catálogo completo editado junto al making of.

Lourdes Villagómez estudió Ciencias de la Comunicación en la Universidad Autónoma Metropolitana de la Ciudad de México y la maestría en Animación Experimental en el California Institute of the Arts de Los Ángeles. Dirige y produce animación en la que mezcla imágenes de la vida diaria y objetos con diferentes técnicas de animación en cine, vídeo e instalación. Su trabajo ha sido presentado en más de cincuenta festivales y ha sido expuesto en espacios como el Museo Nacional de Arte en la Ciudad de México y distintos espacios en Los Ángeles o Milán. En 1999 funda Los Animantes, colectivo de producción y promoción de animación independiente.

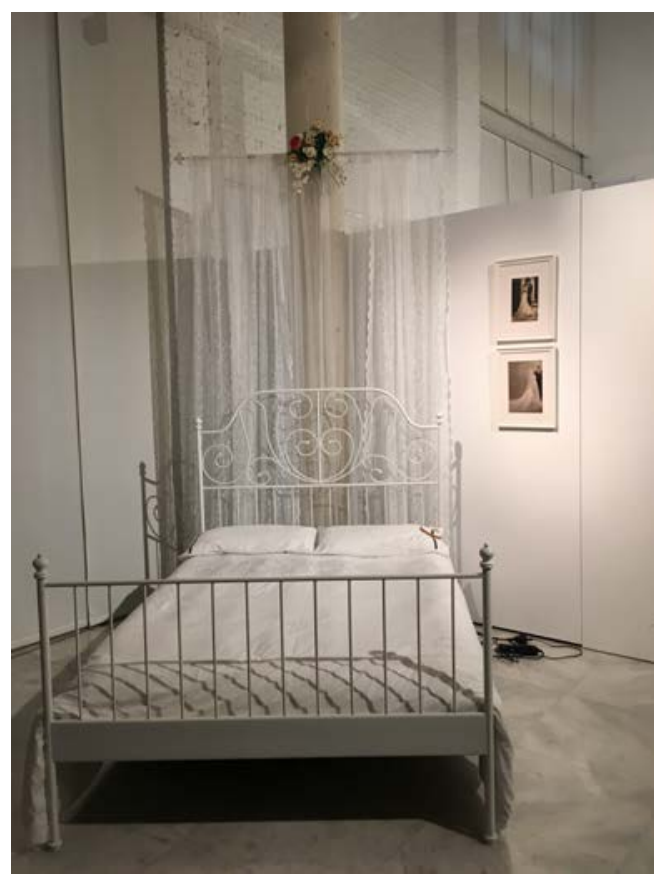

Ejercicio de reconciliación es el título de la pieza que presentó como una continuación del trabajo realizado anteriormente con animación y acciones documentadas con time lapse que exploran distintos aspectos del ámbito doméstico y familiar, mediante el uso de sets a tamaño natural y objetos reales que forman parte de su entorno.

La pieza recrea el montaje de una recámara de "Ikea", el paradigma europeo contemporáneo de la vida familiar feliz y ordenada. Sobre la pared hay tres fotografías de boda: su abuela, tía y madre. Las tres utilizaron el mismo vestido, que heredó y en su momento utilizó para hacer su cortometraje Síndrome de Línea Blanca, para romper con la tradición. La pieza central es una cama blanca de metal que tiene en el cabecero rejas que recuerdan la forma de un corazón y en los pies algo que asemeja rejas de una prisión.

Figura 5. Fotografía. Ejercicio de reconciliación. Montaje en sala.

Coke Riobóo Músico, compositor y animador. Ganador de un premio Goya por su cortometraje El Viaje de Said (2006) un niño marroquí que cruza el Estrecho para viajar al país de las oportunidades y descubre que el mundo no es tan bello como le habían contado. El ruido del mundo (2013), cortometraje animado en plastilina sobre cristal retro iluminado, hace una metáfora sobre el poder del arte para sanar el alma a través de la historia de un compositor con una extraña enfermedad que le hace escuchar todos los ruidos del mundo. A través de su música, intentará encontrar una cura para su desesperación. 
Animación, Conciencia, Mediación. Laboratorio animado para una cultura inclusiva. IV Congreso INTERNACIONAL DE INVESTIGACIÓN EN ARTES VISUALES ANIAV 2019 IMAGEN [N] VISIBLE]

http://dx.doi.org/10.4995/ANIAV.2019.9069

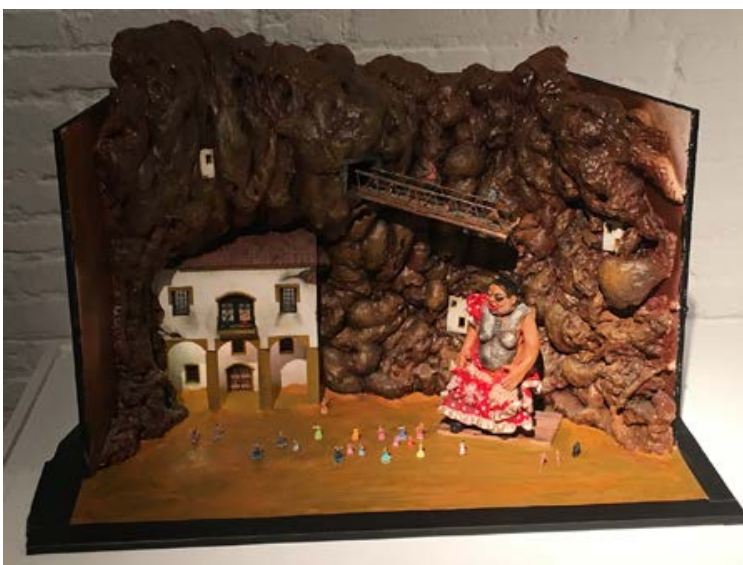

Figura 6. Escenario y personajes a diferente escala de la película Mad in Xpain (2018) Coke Rioboo

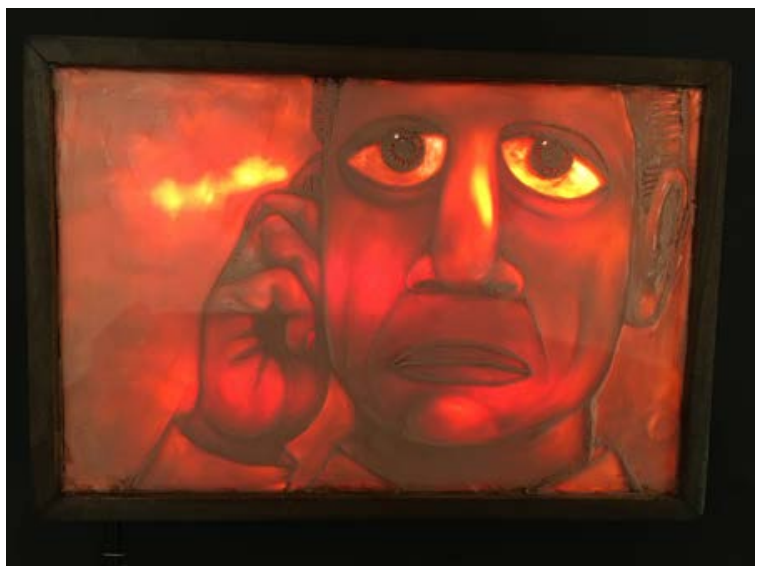

Figura 7. Cuadro retro iluminado con una imagen del filme El ruido del mundo. (2013) Coke Rioboo.

\section{Animación y género rompiendo estereotipos: María Trènor, Emilio Martí y ciclo de mujeres en animación.}

La animación tradicionalmente ha sido una forma de creación elitista y masculinizada. Elitista por la cantidad de medios y conocimientos técnicos que se requieren y masculinizada porque tanto los creadores como las obras de animación han tenido un protagonismo netamente masculino y heterosexual. Sin embargo, el proyecto "Animación, conciencia, mediación" da la vuelta a esta perspectiva: por un lado muestra cómo la animación puede ser realizada y protagonizada por todo tipo de personas, con pocos medios y reutilizando materiales y además, puede servir como una herramienta de empoderamiento, educación y concienciación haciendo hincapié en la perspectiva de género, tanto en la paridad de sus participantes, las temáticas seleccionadas de los filmes a debatir como por el hecho de trabajar desde la pluralidad de miradas y sensibilidades. A partir de estas reflexiones hemos diseñado dos masterclass abiertas al público.

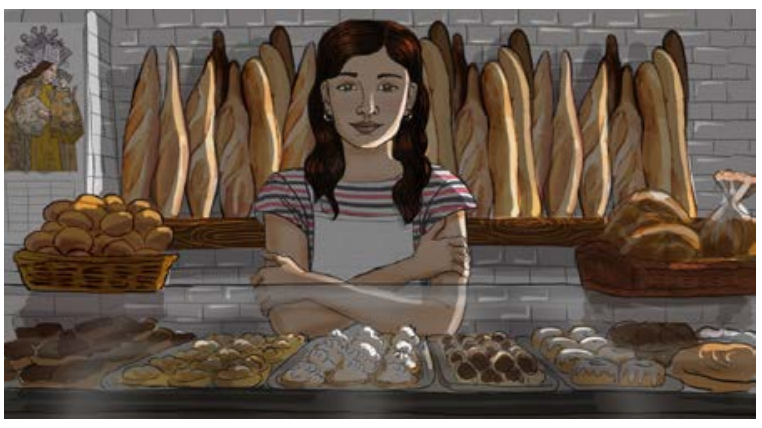

Figura. 8. Fotograma de la panadera del Cabanyal. Una de las tres Protagonistas del corto On estaves tu?. María Trènor.

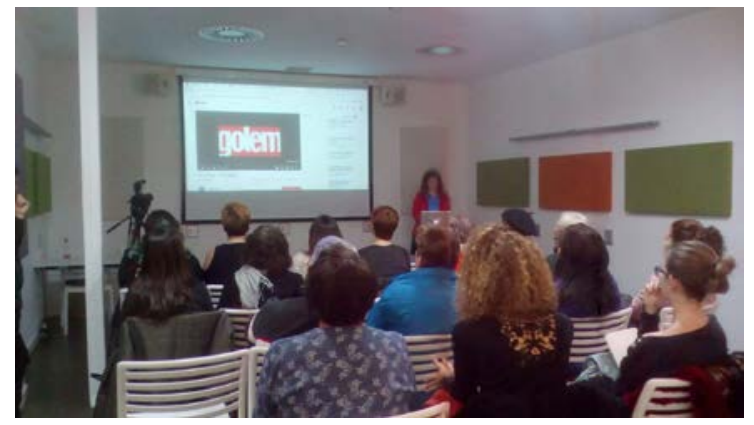

Figura. 9. Foto de la Masterclass. Sala Factoria. Las Naves.

María Trènor Licenciada en Bellas Artes por la Facultad de San Carlos de la UPV de Valencia, autora de Exlibris que fue nominado al Goya como Mejor Cortometraje de Animación Español y Con que la lavaré.

María Trénor desveló el proceso de creación de su próximo corto sobre violencia de género en la sesión diseñada para ello, una masterclass, en la que desvela el proceso de creación de su próximo corto documental titulado On estaves tu?.

Después de la masterclass hubo un interesante debate en el que se señalaron algunos de los problemas sobre cómo abordar la violencia de género en la actualidad: la carencia de educación afectivo-sexual, la inculcación de valores machistas desde la infancia o la errónea culpabilización de las víctimas, entre otros. 


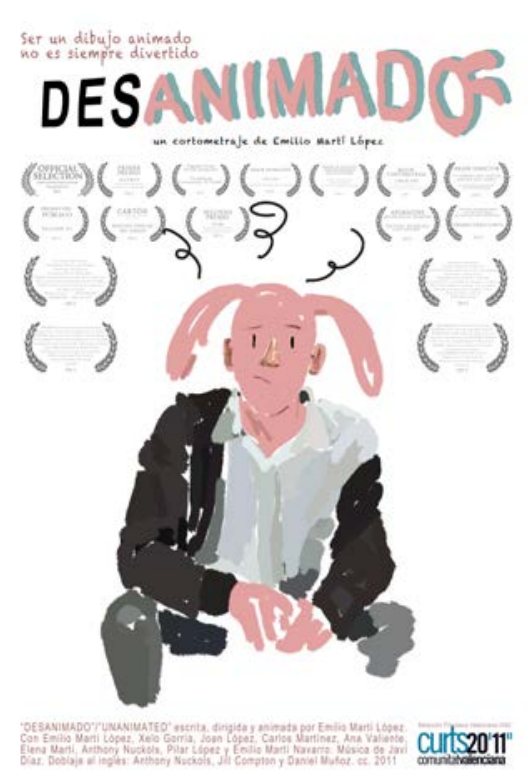

Emilio Martí.

Cineasta y arteterapeuta. Como cineasta en animación su opera prima Desanimado (2011) con el que ha recogido numeroso premios, parte de su producción de arte y teoría en torno a la animación y a las sexualidades LGBT. Para Emilio Martí el dibujo animado aporta otra manera de tratar la diversidad sexual.

Masterclass y proyección. Animación para la diversidad. Cine de animación LGTBIQ con la participación del colectivo Lambda, con proyección de cortometrajes de animación con temática LGTBQ y ponencia subsiguiente para explicar las peculiaridades de un subgénero específico que aún cuesta encontrar en festivales específicos: ocurre todavía, aunque cada vez menos, que festivales de cine LGTBQ apenas tienen animación en sus programas, y que festivales de animación no tengan apenas historias LGTBQ en los suyos.

Como complemento a esta dos acciones abiertas está el "Ciclo de animación y debate en el CCCC de Valencia" Las mujeres animan el mundo, con una selección de películas de las animadoras: Rocío Álvarez, Florence Hernrard, Isabel Herguera, Marie paccou, María Lorenzo y Joanna Quinn. Las obras seleccionadas reivindican el papel protagonista de las mujeres en la animación, donde tradicionalmente han sido invisibilizadas, con la finalidad de ofrecer una mirada abierta y plural sobre el género desde el femenino creador.

Figura. 10. Cartel de la película Desanimado (2011). Obra reivindicativa al derecho a ser diferente. Emilio Martí

\section{El taller en animación. Dando lugar al otro desde el hacer}

Dentro del proyecto se han programado tres talleres:

1) Taller de creación de Taumatropos: juguetes de ilusiones ópticas.

Participan: CEAR, ASOCIACION AMBIT y otros asistentes. Imparte FABLAB Cuenca. Proyecto en fase de desarrollo para la creación de un Laboratorio de Fabricación Digital. En estos espacios los diseños realizados por ordenador se pueden materializar en objetos reales. Su objetivo es convertirnos en una herramienta educativa y creativa abierta para todos los públicos.

2) Taller de stop motion y pixilacion: cadáver exquisito. Un mecanismo de creación colectiva en el que los participantes manipulan y transforman los dibujos de los demás para construir una narración intuitiva e improvisada. Imparte ANIMANSION. Participan: CEAR Y NAYF. 1 sesión. Numero de alumnos Max. 15. Edades de 15 a 20 años .Sala Factoría

3) Taller de animación para mayores: Yo me jubilé, ye ye! . Imparte: MARIO TORRECILLAS. Participa: Hogares compartidos, RAIS y COTLAS. otras asociaciones de mayores. 2 días de taller. Numero de alumnos Max. 15 Con la participación del grupo de Rock Peyfer ${ }^{5}$, de Jubilados, que interpretará diversos temas y ese será uno de los elementos que dinamizará la propuesta de animación.

Los resultados de los talleres se podrán ver en la proyección final que cerrará el proyecto.

\section{CONCLUSIONES}

La realización de todo este proyecto supone un ingente trabajo de coordinación entre los diferentes animadores, los colectivos sociales, las entidades participantes y la comunicación necesaria para difundir tanto la realización de las actividades como sus resultados. No obstante este esfuerzo se ve recompensado por el hecho de haber abierto un camino en el cual la animación cumple una función social que va mucho más allá del estereotipo que se le ha asignado, el de ser un simple vehículo de entretenimiento infantil. Al contrario, personas de todo tipo y condición han podido convivir, realizar trabajos en equipo y observar sus propios resultados in situ, y todo ello ha podido ser documentado por nuestro equipo con la intención de que este proyecto y sus resultados

\footnotetext{
${ }^{5}$ Grupo Peyfer. [Entrada facebook]. Recuperado de https://www.facebook.com/lospeyfer.1/
} 
puedan ser conocidos y exportados más allá de los espacios en los que se ha desarrollado en esta primera edición. Una muestra del éxito es que la exposición fue la más vista en el espacio cultural y que en todos los talleres hubieron listas de espera.

Para próximas ediciones consideramos que se pueden ampliar tanto el equipo de animadores como las actividades previstas así como los espacios y entidades participantes.

\section{FUENTES REFERENCIALES}

Costa, J., Lorenzo, M, Vidal, M, López, M. A. y García, S. (2017). Mantener alejado del alcance de los niños. Animación para adultos. Valencia: Sendemà.

Cueto, R. (Ed.). (2013). Animatropia. Los nuevos caminos del cine de animación. Donostia: Donostia Zinemaldia. Festival de San Sebastian.

Garcia, M.S. (2019, marzo, 3). Animacion inclusiva. [Entrada blog]. Recuperado de https://animacioninclusiva.wordpress.com/

García, M. S. y Sebastian, S. $(2018,10,28)$. Animación, conciencia, mediación. Animación para transformar el mundo.[video] https://vimeo.com/309460328, GAMANprod,

Kriger, J. (2012). Animated realism. A Behind the Scenes. Look at the Animated documentary (2a ed). Oxford: Elsevier/Focal Press.

López Caballero, C. (2014). Metamorfosis, visones fantásticas de Starewitch, Svankmajer y los Hermanos Quay. Barcelona: CCCB y Diputación de Barcelona.

Moreno, A. (2016). La mediación artística. Arte para la transformación social, la inclusión social y el desarrollo comunitario. (1a ed.) Barcelona: Editorial Octaedro.

Wells. P. y Hardstaff, J. (2008). Re-Imagining Animation. London: AVA Books Published.

Zunzunegui, S. (1984). Mirar la imagen. Zarautz: Servicio Editorial, Universidad del País Vasco. 